\title{
The Effect of Agro-meteorological Indices and Planting Date on the Growth, Development and Productivity of Soybean Grown in Vertisols
}

\author{
H. L. Khapediya*, Snjeeda Iqbal, S. K. Sharma, Ranjeet, \\ G. R. Ambawatia and K. K. Singh \\ Nodal officer GKMS \& FASAL - Project, RVSKVV, College of Agriculture, \\ Indore (M.P.), India \\ *Corresponding author
}

\begin{tabular}{|c|c|}
\hline & B S T R A T \\
\hline Keywords & \multirow{4}{*}{$\begin{array}{l}\text { The present investigations entitled "Forecasting of soybean and wheat production using } \\
\text { DSSAT in Malwa Region" was carried out in the experimental farm of AICRP on IFS, } \\
\text { RVSKVV, College of Agriculture, Indore (M.P.) during Kharif and Rabi season of } 2013- \\
14 \text { and } 2014-15 \text {. Phenological observations of soybean recorded at Anthesis days, first } \\
\text { pod days, first seed days, physiological maturity day stage, showed that duration, growing } \\
\text { degree days(GDD), and helio thermal units (HTU) were more in D2, } 2^{\text {nd }} \text { July sown date } \\
\text { followed by D3, } 12^{\text {th }} \text { July and D1, 22th July sown dates during both the years of } \\
\text { experimentation. The variety JS-335 absorbed more heat units at physiological maturity at } \\
\text { its growing degree days (GDD) and Helio-thermal units (HTU) were more than JS93-05 } \\
\text { and JS95-60 during both year of the experiment. Heat use efficiency for grain yield was } \\
\text { highest in D2, date ( } 2^{\text {nd }} \text { July and } 25^{\text {th }} \text { November) sown crop than rest sowing dates. The } \\
\text { variety JS-335 registered higher HUE than variety JS93-05 both the years of } \\
\text { experimenting. }\end{array}$} \\
\hline $\begin{array}{l}\text { Growing Degree } \\
\text { days, Heliothremal } \\
\text { unit, Soybean }\end{array}$ & \\
\hline Article Info & \\
\hline $\begin{array}{l}\text { Accepted: } \\
20 \text { December } 2020 \\
\text { Available Online: } \\
10 \text { January } 2021\end{array}$ & \\
\hline
\end{tabular}

\section{Introduction}

Soybean is considered as the most despised member of oilseeds and pulses in our country. This is probably due to the fact that even under minimum agricultural inputs and management practices it fetches profitable returns to its growers. In recent years, soybean has assumed important position in India as it is one the most stable Kharif crops yielding cost effective production in varied agro-climatic conditions unlike Kharif pulses and oilseeds of our country. Under scientific management conditions soybean cultivation yields the highest productivity, net returns and builds up soil fertility as well (Kumar et al., 2008).

Cultivation of soybean on large scale was started in selected state during the year 19711972 (Wasnik 1986). The temperature is an important meteorological variables that affect plant growth and development (Lande and Woodward, 1988). Day light and bright sunshine hours play in important role in growth and development of soybean crop. 
Same varieties flower in less than 30 days after emergence if exposed to day light less than twelve hours (Beard and Knowles 1973).

Soybean is widely cultivated in tropical, subtropical and warm temperature regions of the world. Soybean grows well in warm and most climate. A temperature of $26^{\circ} \mathrm{C}$ to $30^{\circ} \mathrm{C}$ appears to be the optimum for most of the verities. Soil temperature of $15.5{ }^{\circ} \mathrm{C}$ or above favour rapid germination and vigorous seedling growth. The minimum temperature for effective growth is about $10^{\circ} \mathrm{C}$. Days length is the key factor in most of the soybean varieties as they are short day plant and are sensitive to photoperiods. Most of the varieties will flower and mature quickly in grown under condition were the day length is less than $14 \mathrm{hrs}$ provided that temperatures are also favorable (Patil et al., 2014).

\section{Materials and Methods}

The present investigations entitled "Forecasting of soybean and wheat production using DSSAT in Malwa Region" was carried out in the experimental farm of AICRP on IFS, RVSKVV, College of Agriculture, Indore (M.P.) during Kharif and Rabi season of 2013-14 and 2014-15. The model establishment part constitutes analysis, calibration and validation of the model with site specific data under current conditions. The Indore Center is located Central highlands it represent Malwa region of Madhya Pradesh which is situated at $76^{\circ} 54^{\prime}$ E longitudes and $22^{\circ} 43^{\prime} \mathrm{N}$ latitudes at an altitudes of 567, above MSL. To study area comprised of Indore, Dewas, Shajapur, Rajgarh, Mandsaur, Ratlam and Neemuch district of western Madhya Pradesh. The Weather data during field experiment conducted the Kharif and Rabi Season of 2013-14 and 2014-15 are obtained from Agro-meteorological observatory of College of Agriculture, Indore. The soil of the area is medium, deep and shallow black soils, mostly derived from Daccan trap. They are called black cotton soils and classified as vertisols. Experimental details Kharif Season soybean crop variety name V1. JS-335, V2: JS 93-05 and V3: JS 95-60, experimental design split plot, sowing method direct seeded, sowing depth 4-6 cm, replication 4, treatment 12 , sowing date D1: 22th Jun, D2: $02^{\text {nd }}$ July, D3: $12^{\text {th }}$ July and D4: 22th July.

Agro-meteorological indices like growing degree days (GDD) and Heliothermal unit (HTU), were computed using weather data. the rainfall during Kharif season at Indore $900.0 \mathrm{~mm}$. the growing degree days were computed by considering the base temperature of $10.0{ }^{\circ} \mathrm{C}$ for the soybean crop. The sum of degree days for the completion of each phenophase were obtained by using following formula.

Acculated GDD ${ }^{\circ} C$ day $)=\sum_{i=d F}^{a=d s}(\bar{T}-T b)$

Where: ${ }^{\bar{T}}$ (Daily mean air temperature in ${ }^{\circ} \mathrm{C}=\frac{(T \max .+T \text { min. })}{2}$

$\mathrm{Tb}=$ Base temperature $\left(10{ }^{0} \mathrm{C}\right)$

$\mathrm{ds}=$ Date of emergence

$\mathrm{dh}=$ Date of Harvest

Base Temperature of the soybean crop are $10.0{ }^{\circ} \mathrm{C}$ : the helio-thermal unit for a given days represents the product of GDD and the actual hours of bright sunshine for that day. The sum of HTU for the duration of each phenophase was determine by using the following formula

Acculated HTU $\left({ }^{\circ} \mathrm{C}\right.$ day $)=\sum_{i=d s}^{i=d \hbar}[(\bar{T}-T b) i \times D i]$

Where

HTU = Helio-thermal units

$\mathrm{T}=$ Mean daily temperature $\left({ }^{\mathrm{o}} \mathrm{C}\right)$

$\mathrm{Tb}=$ Base temperature 
$\mathrm{ds}=$ Date of emergence

$\mathrm{dh}=$ Date of Harvest

$\mathrm{D}=$ Hours of bright sunshine

\section{Results and Discussion}

Many environmental factors affect the distribution, growth and biological development of plants, but most relate to climate. In terms of climatic indictor variables based on standard climate data, air temperature and precipitation are the most important. The former is particularly important because it is linked both directly and indirectly to other indicators such as soil temperature, day length (photoperiod) and solar radiation. Moreover, the cumulative effect of daily air temperature over the longer term is an important indicator of plant growth potential and crop yield has been found to statistically explain $95 \%$ of the variability in plant development. Temperature is also the main limiting factor for plant growth, especially in temperate zones and at high latitudes. Various climatic indices based on air temperature that show the heat accumulation necessary for plant development have been proposed for use primarily in agricultural management processes.

Duration (Days): 50\% Flowering (2013-14) in Soybeanfollowing table no. 1 Therefore, phenological development in relation to growth duration (days), the soybean cultivar JS-335 sown on D2: $2^{\text {nd }}$ July took the maximum number of days (41 days) to attend anthesis stage followed by D1: $22^{\text {nd }}$ June and D3: $12^{\text {th }}$ July(39 days) and lowest in case of D4: $22^{\text {nd }}$ July (35 days). While, in case of JS93-05sown on D1: $22^{\text {nd }}$ June took the maximum number of days ( 35 days) to attend anthesis stage followed by D2: $2^{\text {nd }}$ July (30 days), D3: $12^{\text {th }}$ July and lowest in D4: $22^{\text {nd }}$ July (29 days). Almost similar trend was observed for the cultivar JS-9560. The observed values of number of days required to attend 50\% Flowering for different varieties of soybean planted on different dates ranged from 27-41 days. It was higher in D1 and decreased with delaying in sowing as observed in D3.

The simulated values also followed the same trend as in case of observed values. The predicted values are in general 2 days higher then observed values. Almost similar trend was observed for the year 2014. First Pod phase (2013-14) the observed values of number of days required to attend first pod filling phase for different varieties of soybean planted on different dates ranged from 40-52 days. It was higher in D1 and decreased with delaying in sowing as compared to D4. The simulated values also followed the same trend as in case of observed values. The predicted values are in general 2 days higher then observed values. Almost similar trend was observed for the year 2014. First seed day phase (2013-14)The observed values of number of days required to attend First seed day phase for different varieties of soybean planted on different dates ranged from 50-65 day. It was higher in D1 and decreased with delaying in sowing as compared to D4. The simulated values also followed the same trend as in case of observed values. The predicted values are in general 2 days higher then observed values. Almost similar trend was observed for the year 2014. Physiological Maturity day (2013-14) the observed values of number of days required to attend Physiological Maturity day phase for different varieties of soybean planted on different dates ranged from 70-90 day. It was higher in D1 and decreased with delaying in sowing as compared to D4. The simulated values also followed the same trend as in case of observed values. The predicted values are in general 3 days higher then observed values. Almost similar trend was observed for the year 2014. 
Table.1 Duration at different phenophase of soybean crop under different treatment

\begin{tabular}{|c|c|c|c|c|c|c|c|c|c|c|c|c|c|c|c|c|}
\hline \multirow{4}{*}{$\begin{array}{l}\text { Treatment } \\
\text { Cultivars }\end{array}$} & \multicolumn{16}{|c|}{ Growing Degree days ( ${ }^{\circ} \mathrm{C}$ Days) } \\
\hline & \multicolumn{8}{|c|}{ Year 2013-14 } & \multicolumn{8}{|c|}{ Year 2014-15 } \\
\hline & \multicolumn{2}{|c|}{$D_{1} 2^{\text {nd }}$ June } & \multicolumn{2}{|c|}{$\mathrm{D}_{2} 2^{\text {nd }}$ July } & \multicolumn{2}{|c|}{$\mathbf{D}_{\mathbf{3}}, \mathbf{1 2}^{\text {th }} \mathrm{JULY}$} & \multicolumn{2}{|c|}{$D_{4}, 22^{\text {nd }} J U L Y$} & \multicolumn{2}{|c|}{$D_{1} 22^{\text {nd }}$ June } & \multicolumn{2}{|c|}{$\mathrm{D}_{2} 2^{\text {nd }}$ July } & \multicolumn{2}{|c|}{$\mathrm{D}_{\mathbf{3}}, 12^{\text {th }} \mathrm{JULY}$} & \multicolumn{2}{|c|}{$D_{4}, 22^{\text {nd }}$ JULY } \\
\hline & SIM & OBS & SIM & OBS & SIM & OBS & SIM & OBS & SIM & OBS & SIM & OBS & SIM & OBS & SIM & OBS \\
\hline \multicolumn{17}{|c|}{ Anthesis Phase } \\
\hline JS-335 & 39 & 37 & 41 & 39 & 39 & 38 & 35 & 37 & 39 & 41 & 38 & 37 & 36 & 37 & 35 & 36 \\
\hline JS 93-05 & 35 & 33 & 32 & 30 & 29 & 30 & 29 & 28 & 33 & 31 & 32 & 32 & 31 & 30 & 30 & 29 \\
\hline JS 95-60 & 33 & 31 & 30 & 28 & 29 & 27 & 29 & 30 & 32 & 29 & 30 & 31 & 29 & 31 & 28 & 27 \\
\hline \multicolumn{17}{|c|}{ First Pod Phase } \\
\hline JS-335 & 50 & 48 & 48 & 46 & 46 & 47 & 44 & 43 & 52 & 50 & 50 & 49 & 47 & 45 & 45 & 43 \\
\hline JS 93-05 & 48 & 46 & 47 & 45 & 46 & 44 & 45 & 43 & 49 & 48 & 47 & 45 & 45 & 43 & 43 & 41 \\
\hline JS 95-60 & 49 & 47 & 48 & 46 & 45 & 44 & 46 & 43 & 47 & 45 & 46 & 44 & 47 & 43 & 42 & 41 \\
\hline \multicolumn{17}{|c|}{ First Seed day } \\
\hline JS-335 & 62 & 60 & 58 & 57 & 57 & 55 & 54 & 52 & 62 & 60 & 58 & 57 & 57 & 55 & 54 & 52 \\
\hline JS 93-05 & 56 & 55 & 55 & 54 & 54 & 51 & 53 & 51 & 56 & 55 & 55 & 54 & 54 & 51 & 53 & 51 \\
\hline JS 95-60 & 58 & 56 & 56 & 55 & 55 & 54 & 53 & 52 & 58 & 56 & 56 & 55 & 55 & 54 & 53 & 52 \\
\hline \multicolumn{17}{|c|}{ Physiological Maturity day } \\
\hline JS-335 & 98 & 96 & 96 & 97 & 93 & 91 & 91 & 88 & 98 & 96 & 97 & 94 & 95 & 93 & 92 & 90 \\
\hline JS 93-05 & 83 & 81 & 81 & 79 & 79 & 76 & 77 & 75 & 79 & 77 & 77 & 75 & 76 & 74 & 73 & 71 \\
\hline JS 95-60 & 78 & 76 & 77 & 75 & 75 & 74 & 74 & 72 & 76 & 74 & 75 & 73 & 76 & 75 & 74 & 70 \\
\hline
\end{tabular}


Table.2 Growing Degree day (GDD) at different phenophase of soybean crop under different treatment

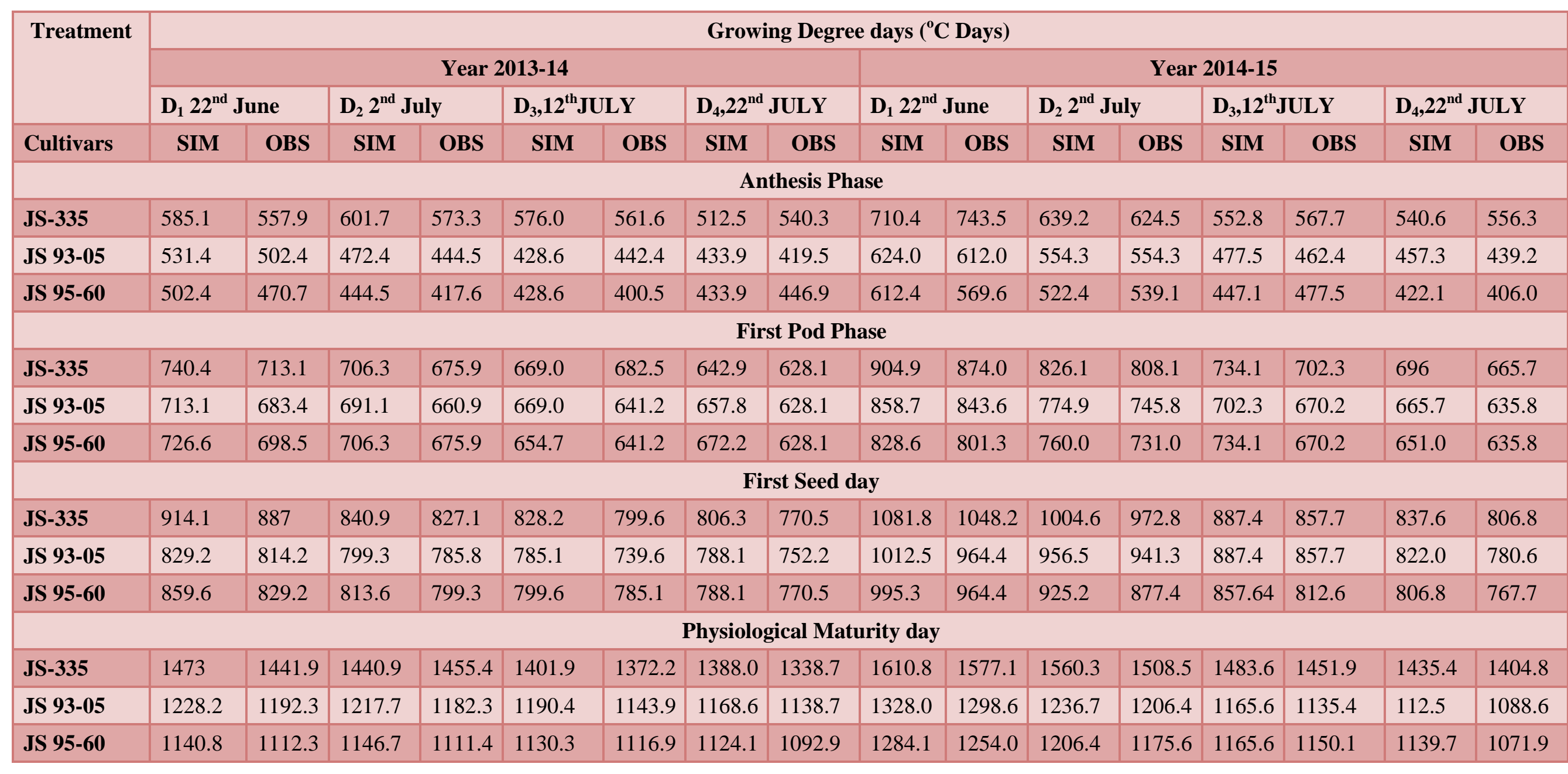


Table.3 Helio-thermal units (HTU) at different phenophase of soybean crop under different treatment

\begin{tabular}{|c|c|c|c|c|c|c|c|c|c|c|c|c|c|c|c|c|}
\hline \multirow{4}{*}{$\begin{array}{l}\text { Treatment } \\
\text { Cultivars } \\
\end{array}$} & \multicolumn{16}{|c|}{ Growing Degree days ( ${ }^{\circ} \mathrm{C}$ Days) } \\
\hline & \multicolumn{8}{|c|}{ Year 2013-14 } & \multicolumn{8}{|c|}{ Year 2014-15 } \\
\hline & \multicolumn{2}{|c|}{$D_{1} 2^{\text {nd }}$ June } & \multicolumn{2}{|c|}{$D_{2} 2^{\text {nd }}$ July } & \multicolumn{2}{|c|}{$D_{3}, 12^{\text {th }}$ JULY } & \multicolumn{2}{|c|}{$D_{4}, 22^{\text {nd }}$ JULY } & \multicolumn{2}{|c|}{$D_{1} 22^{\text {nd }}$ June } & \multicolumn{2}{|c|}{$\mathrm{D}_{2} 2^{\text {nd }}$ July } & \multicolumn{2}{|c|}{$D_{3}, 12^{\text {th }}$ JULY } & \multicolumn{2}{|c|}{$D_{4}, 22^{\text {nd }}$ JULY } \\
\hline & SIM & OBS & SIM & OBS & SIM & OBS & SIM & OBS & SIM & OBS & SIM & OBS & SIM & OBS & SIM & OBS \\
\hline \multicolumn{17}{|c|}{ Anthesis Phase } \\
\hline JS-335 & 1960.9 & 1873.9 & 2269.5 & 2250.6 & 2038.6 & 1972.7 & 1849.3 & 1947.3 & 2600.1 & 2631.6 & 1829.4 & 1800.8 & 1179.9 & 1220.1 & 877.1 & 941.5 \\
\hline JS 93-05 & 1819.4 & 1600.4 & 1971.9 & 1701.8 & 1533.4 & 1548.4 & 1608.3 & 1542.3 & 2440.5 & 2403.0 & 1712.7 & 1712.7 & 1087.3 & 1075.1 & 655.1 & 644.3 \\
\hline JS 95-60 & 1660.4 & 1629.0 & 1701.8 & 1587.1 & 1533.4 & 1455.5 & 1608.3 & 1676.7 & 2405.6 & 2371.4 & 1620.0 & 1636.7 & 1052.3 & 1087.3 & 637.4 & 603.7 \\
\hline \multicolumn{17}{|c|}{ First Pod Phase } \\
\hline JS-335 & 2659.0 & 2601.5 & 2689.9 & 2592.9 & 2566.0 & 2636.3 & 2656.9 & 2544.1 & 2892.0 & 2856.2 & 2057.7 & 2046.8 & 1609.4 & 1493.5 & 1372.6 & 1211.8 \\
\hline JS 93-05 & 2789.3 & 2641.2 & 2817.0 & 2676.0 & 2566.0 & 2420.0 & 2786.3 & 2544.1 & 2833.4 & 2824.3 & 2006.3 & 1960.4 & 1493.5 & 1410.7 & 1211.8 & 1130.3 \\
\hline JS 95-60 & 2831.9 & 2754.0 & 2821.0 & 2724.0 & 2479.2 & 2420.0 & 2867.8 & 2544.1 & 2795.7 & 2748.5 & 1966.0 & 1930.7 & 1609.4 & 1410.7 & 1200.0 & 1130.3 \\
\hline \multicolumn{17}{|c|}{ First Seed day } \\
\hline JS-335 & 3526.1 & 3405.5 & 3372.3 & 3353.5 & 3468.7 & 3259.3 & 4388.0 & 3982.7 & 3526.1 & 3405.5 & 3372.3 & 3353.5 & 3468.7 & 3259.3 & 4388.0 & 3982.7 \\
\hline JS 93-05 & 3174.2 & 3126.2 & 3196.4 & 3137.2 & 3130.0 & 2779.0 & 4183.8 & 3768.3 & 3174.2 & 3126.2 & 3196.4 & 3137.2 & 3130.0 & 2779.0 & 4183.8 & 3768.3 \\
\hline JS 95-60 & 3271.2 & 3174.2 & 3283.2 & 3196.4 & 3259.3 & 3130.0 & 4183.8 & 3982.7 & 3271.2 & 3174.2 & 3283.2 & 3196.4 & 3259.3 & 3130.0 & 4183.8 & 3982.7 \\
\hline \multicolumn{17}{|c|}{ Physiological Maturity day } \\
\hline JS-335 & 7542.4 & 7200.0 & 7909.0 & 8045.5 & 7953.4 & 7824.0 & 8863.1 & 8266.8 & 1610.8 & 1577.1 & 1560.3 & 1508.5 & 1483.6 & 1451.9 & 1435.4 & 1404.8 \\
\hline JS 93-05 & 5824.2 & 5408.7 & 6476.5 & 6292.3 & 6558.2 & 6032.7 & 6855.2 & 6633.3 & 1328.0 & 1298.6 & 1236.7 & 1206.4 & 1165.6 & 1135.4 & 112.5 & 1088.6 \\
\hline JS 95-60 & 4810.9 & 4508.2 & 6025.4 & 5769.3 & 5920.8 & 5913.4 & 6558.8 & 6387.6 & 1284.1 & 1254.0 & 1206.4 & 1175.6 & 1165.6 & 1150.1 & 1139.7 & 1071.9 \\
\hline
\end{tabular}


Table.4 Soybean Grain Yield Year Wise $\left(\mathrm{kg}[\mathrm{dm}] \mathrm{ha}^{-1}\right)$

\begin{tabular}{|c|c|c|c|c|c|c|}
\hline \multicolumn{7}{|c|}{ Soybean Cultivars } \\
\hline \multirow[t]{2}{*}{ Year } & \multicolumn{2}{|c|}{ JS-335 } & \multicolumn{2}{|c|}{ JS93-05 } & \multicolumn{2}{|c|}{ JS95-60 } \\
\hline & $\begin{array}{c}\text { SIM } \\
\text { kg/ha }\end{array}$ & $\begin{array}{c}\text { OBS } \\
\text { Kg/ha }\end{array}$ & $\begin{array}{c}\text { SIM } \\
\text { kg/ha }\end{array}$ & $\begin{array}{r}\text { OBS } \\
\text { kg/ha }\end{array}$ & $\begin{array}{c}\text { SIM } \\
\text { kg/ha }\end{array}$ & $\begin{array}{r}\text { OBS } \\
\text { kg/ha }\end{array}$ \\
\hline 2012 & $\begin{array}{l}1238 \\
(7 \%)\end{array}$ & 1150 & $\begin{array}{c}1295 \\
(15 \%)\end{array}$ & 1095 & $\begin{array}{c}1237 \\
16.7 \%\end{array}$ & 1030 \\
\hline 2013 & $\begin{array}{l}1205 \\
(7 \%)\end{array}$ & 1120 & $\begin{array}{c}1384 \\
(7.6 \%)\end{array}$ & 1278 & $\begin{array}{c}1331 \\
(24.1)\end{array}$ & 1010 \\
\hline 2014 & $\begin{array}{c}1659 \\
(14 \%)\end{array}$ & 1425 & $\begin{array}{c}1288 \\
(11.8 \%)\end{array}$ & 1135 & $\begin{array}{c}1669 \\
(18.8 \%)\end{array}$ & 1355 \\
\hline 2015 & $\begin{array}{c}1580 \\
(15 \%)\end{array}$ & 1340 & $\begin{array}{c}1590 \\
(12.8 \%)\end{array}$ & 1385 & $\begin{array}{c}1570 \\
(5.09 \%)\end{array}$ & 1490 \\
\hline
\end{tabular}

Values given in the parenthesis are \% increase in Actual yield over simulated yield

Growing Degree days (GDD): Growing Degree Days (GDD) of different varieties of soybean planted on different dates has been calculated and are presented in table no. 2 through 50\% Flowering (2013-14)The observed accumulated GDD was highest for JS-335 in all the sowing dates followed by JS93-05 and lowest in JS95-60, similar trend was observed in case of simulated values of GDD. The observed and simulated accumulated GDD required for JS-335 planted on different dates was 557.9 and 585.1 for D1, 573.3 and 601.7 for D2, 561 and 576 for D3 and 540.3 and 512.5 for D4, respectively. The observed and simulated accumulated GDD required for JS93-05 planted on different dates was 502.4 and 531.4 for D1, 444.5 and 472.4 for D2, 442.4 and 428.6 for D3 and 419.5 and 433.9 for D4, respectively. The variety JS95-60 took 470.7 , 417.6, 4005, 446.9 accumulated GDD for D1, D2, D3 and D4 dates of sowing respectively. The simulated values were also close to observed one and it was 502.4, 444.5, 428.6 and 433.9 for D1, D2, D3 and D4 dates of sowing respectively. All most similar trend was observed for the year 2014. First Pod phase (2013-14) The observed accumulated GDD was highest for JS-335 in all the sowing dates followed by JS93-05 and lowest in
JS95-60, similar trend was observed in case of simulated values of GDD. The observed and simulated accumulated GDD required for JS-335 planted on different dates was 713.1 and 740.4 for D1, 675.9 and 706.3 for D2, 682.5 and 669.0 for D3 and 628.1 and 672.2 for D4, respectively. The observed and simulated accumulated GDD required for JS93-05 planted on different dates was 683.4 and 713.1 for D1, 660.9 and 691.1 for D2, 641.2 and 669.0 for D3 and 628.1 and 657.8 for D4, respectively. The variety JS95-60 took 698.5, 726.6, 675.9, and 706.3 accumulated GDD for D1, D2, D3 and D4 dates of sowing respectively. The simulated values were also close to observed one and it was $641.2,654.7,628.1$, and 628.1 for D1, D2, D3 and D4 dates of sowing respectively. All most similar trend was observed for the year 2014. First seed day phase (2013-14) The observed accumulated GDD was highest for JS-335 in all the sowing dates followed by JS93-05 and lowest in JS95-60, similar trend was observed in case of simulated values of GDD.

The observed and simulated accumulated GDD required for JS-335 planted on different dates was 887 and 914.1 for D1, 827.1 and 840.9 for D2, 799.6 and 828.2 for D3 and 
770.5 and 806.3 for D4, respectively. The observed and simulated accumulated GDD required for JS93-05 planted on different dates was 814.2 and 829.2 for D1, 785.8 and 799.3 for D2, 739.6 and 785.1 for D3 and 752.2 and 788.1 for D4, respectively. The variety JS95-60 took 829.2, 859.6, 799.3, and 813.6 accumulated GDD for D1, D2, D3 and D4 dates of sowing respectively. The simulated values were also close to observed one and it was 785.1, 799.6, 770.5, and 788.1 for D1, D2, D3 and D4 dates of sowing respectively. All most similar trend was observed for the year 2014. Physiological Maturity day (2013-14) The observed accumulated GDD was highest for JS-335 in all the sowing dates followed by JS93-05 and lowest in JS95-60, similar trend was observed in case of simulated values of GDD. The observed and simulated accumulated GDD required for JS-335 planted on different dates was 1441.9 and 1473 for D1, 1455.4 and 1440.9 for D2, 1372.2 and 1401.9 for D3 and 1338.7 and 1388 for D4, respectively. The observed and simulated accumulated GDD required for JS93-05 planted on different dates was 1192.3 and 1228.2 for D1, 1182.3 and 1217.7 for D2, 1143.9 and 1190.4 for D3 and 1138.7 and 1168.6 for D4, respectively. The variety JS95-60 took 1112.3, 1140.8, 1111.4, and 1146.7 accumulated GDD for D1, D2, D3 and D4 dates of sowing respectively. The simulated values were also close to observed one and it was 1116.9, 1130.3, 1092.9, and 1124.1 for D1, D2, D3 and D4 dates of sowing respectively. All most similar trend was observed for the year 2014.

Helio Thermal Units (HTU): Data presenting to helio thermal units for attending the different phase in soybean during year 2013-14 and 2014-15, are presented in table no. $50 \%$ Flowering: The observed and simulated HTU required for 50\% Flowering was 1873.9 and 1960.9 , respectively for JS335 in case of D1: $22^{\text {nd }}$ June, 2250.6 and
2269.5 for D2, 1972.7 and 2038.6 for D3 and 1947.3 and 1849.3 for D4. The observed and simulated HTU required for 50\% Flowering was 1600.4 and 1819.4, respectively for JS9305 in case of D1: $22^{\text {nd }}$ June, 1701.8 and 1971.9 for D2, 1548.4 and 1533.4 for D3 and 1542.3 and 1608.3 for D4. The cultivar JS9560 took 1629.4 (observed) and 1660.4 (predicted) HTU to attend anthesis stage in case of D1: $22^{\text {nd }}$ June, 1587.1 (observed) and 1701.8(predicted) for D2, 1455.5 (observed) and 1533.4 (predicted) for D3, and 1676.7 (observed) and 1608.3 for D4 (predicted).

First pod filling phase: The observed and simulated HTU required for first pod filling phase year 2013-14 was 2601.5 and 2659.0, respectively for JS-335 in case of D1: $22^{\text {nd }}$ June, 2592.9 and 2689.9 for D2, 2636.3 and 2566.0 for D3 and 2544.1 and 2656.9 for D4. The observed and simulated HTU required for first pod filling phase was 2641.2 and 2789.3, respectively for JS-9305 in case of D1: $22^{\text {nd }}$ June, 2676.0 and 2817.0 for D2, 2420.0and 2566.0 for D3 and 2544.1 and 2786.3 for D4. The cultivar JS-9560 took 2754.0(observed) and 2831.9(predicted) HTU to attend first pod filling stage in case of D1: $22^{\text {nd }}$ June, 2724.0 (observed) and 2821.0 (predicted) for D2, 2420.0 (observed) and 2479.2 (predicted) for D3, and 2544.1 (observed) and 2867.8 for D4 (predicted). The observed and simulated HTU required for first pod filling phase (year 201415) was 3405.5 and 3526.1 , respectively for JS-335 in case of D1: $22^{\text {nd }}$ June, 3353.5 and 3372.3 for D2, 3259.3 and 3468.7 for D3 and 3982.7 and 4388.0 for D4. The observed and simulated HTU required for First seed day phase was 3126.2 and 3174.2, respectively for JS93-05 in case of D1: $22^{\text {nd }}$ June, 3137.2 and 3196.4 for D2, 2779.0 and 3130.0 for D3 and 3768.3 and 4183.8 D4. The cultivar JS95-60 took 3174.2 (observed) and 3271.2 (predicted) HTU to attend First seed day filling stage in case of D1: $22^{\text {nd }}$ June, 3196.4 (observed) and 3283.2 (predicted) for D2, 
3130 (observed) and 3259.3 (predicted) for D3, and 3982.7 (observed) and 4183.8 for D4 (predicted).

Physiological Maturity day phase: The observed and simulated HTU required for Physiological Maturity day phase was 7200 and 7542.4, respectively for JS-335 in case of D1: $22^{\text {nd }}$ June, 8045.2 and 7909.0 for D2, 7824.0 and 7953.4 for D3 and 8266.8 and 8863.1 for D4. The observed and simulated HTU required for Physiological Maturity day phase was 5408.7 and 5824.2, respectively for JS93-05 in case of D1: $22^{\text {nd }}$ June, 6292.3 and 6476.5 for D2, 6032.7 and 6558.2 for D3 and 6633.3 and 6855.2 for D4. The cultivar JS9560 took 4508.2 (observed) and 4810.9 (predicted) HTU to attend Physiological Maturity day phase stage in case of D1: $22^{\text {nd }}$ June, 5769.3 (observed) and 6025.4 (predicted) for D2, 5913.4 (observed) and 5920.8 (predicted) for D3, and 6387.6 (observed) and 6558.8 for D4 (predicted).

\section{Yield}

Observed and simulated seed yield of popular cultivars of soybean during different years: Observed and simulated seed yield of three cultivars of soybean for the year2012, 2013, 2014 1nd 2015 has been presented in Table 4.0 and Fig 1.0. It is evident that the simulated grain yield are for the cultivar JS335 ranged from 1205 to $1650 \mathrm{kgha}^{-1}$ and actual (observed) grain yield ranged from 1120-1425 during 2012-2015. The simulated grain yield was close to observed one and it was slightly higher (7 to 15\%) with a \% RMSE at $5 \%$ of 4.9 which is non-significant.

For the cultivar JS93-05 it ranged from 1295 to 1590 and 1095 to $1590 \mathrm{kgha}^{-1}$ for simulated and observed data, respectively during 2012 to 2015 . The simulated grain yields were 7 to $15 \%$ higher than observed grain yields, but $\%$ RSME at 5\% was 5.7 which were non- significant. Similarly, in case of JS 9660 the grain yields ranged from 1237 to $1669 \mathrm{kgha}^{-1}$ and 1010 to $1490 \mathrm{kgha}^{-1}$ for simulated and observed grain yields, respectively. The differences between simulated and observed values were found to be large in case of JS9560 as compared to JS-335 and JS93-05. The \% RMSE was 7.2 in case of JS95-60.

Results suggest an acceptable agreement between simulated and observed seed yields. Thus the performance of DSSAT model is quite satisfactory for the prediction of soybean productivity in the region.

In conclusion the phenological observations of soybean recorded at Anthesis days, first pod days, first seed days, physiological maturity day stage, showed that duration, growing degree days (GDD), and helio thermal units (HTU) were more in D2, $2^{\text {nd }}$ July sown date followed by D3, $12^{\text {th }}$ July and D1, 22th July sown dates during both the years of experimentation. The variety JS-335 absorbed more heat units at physiological maturity at its growing degree days (GDD) and Helio-thermal units (HTU) were more than JS93-05 and JS95-60 during both year of the experiment. Heat use efficiency for grain yield was highest in D2, date ( $2^{\text {nd }}$ July and $25^{\text {th }}$ November) sown crop than rest sowing dates. The variety JS-335 registered higher HUE than variety JS93-05 both the years of experimenting.

\section{References}

Khapedia, H. L., Ranjeet, S. K. Sharma, R. Sikarwar and Inder Singh Mridha, (2018) "Forecasting Wheat Productivity and Production of Madhya Pradesh, India, Using Autoregressive Integrated Moving Average Models" International Journal of Current Microbiology and Applied Sciences ISSN: 2319-7706 Special Issue-7 pp. 
4693-4705

Kumar Anil., Pandey V., Shekh A.M. and Kumar Manoj (2008) Growth and yield response of soybean (Glycine max L.,) in relation to temperature, photoperiod and sunshine duration at Anand, Gujarat., India. Amarican-Eurasain Journal of Agronomy 1 (2) PP 45-50.

Londe S.P., and Woodward F.I. (1988). Plant and temperature symposia of the society for experimental biology, No. 42

Mujalde, S., S. K. Choudhary, D. H. Ranade and Ranjeet (2018) "Seed Priming: A New Technology for Improve Early Seed Emergence \& Establishments of Crops in Rainfed Conditions of India" " International Journal of Current Microbiology and Applied Sciences ISSN: 2319-7706 Special Issue-7 pp. 3638-3641 (2018)

Patil S.R., Jadhav M.G. and Jadhav J.D. (2014) Growing degree days (GDD), heliothrermal units (HTU) as influenced by sowing periods and verities in Soybean. International
Journal of plant sciences. 9 (2) PP 312318.

Ranjeet, H. L. Khapedia, Sanjay Sharma, Rvindra Singh Sikarwar and Narendra Gujar, (2018) "Growth in Area, Yield and Production of Major Crops in Malwa Plateau Agro Climatic Zone of Madhya Pradesh" International Journal of Current Microbiology and Applied Sciences ISSN: 2319-7706 Special Issue-7 pp. 4685-469 (2018)

Sanjay Sharma, Ranjeet, Pratiksha Dubey, Indra Singh Mirdha and Ravindra Singh Sikarwar (2018) "Precipitation Trend Analysis By Mann-Kendall Test of Different Districts Of Malwa Agroclimatic Zone"., Environment and Ecology Volume 39 (3), JanuaryMarch 2018

Wasnik M.D. (1986). Prospects and problem of soybean development in India. Annual workshop of all Indian coordinated research projects on soybean. MACS Res., Institute Pune PP 22-25.

\section{How to cite this article:}

Khapediya, H. L., Snjeeda Iqbal, S. K. Sharma, Ranjeet, G. R. Ambawatia and Singh, K. K. 2021. The Effect of Agro-meteorological Indices and Planting Date on the Growth, Development and Productivity of Soybean Grown in Vertisols. Int.J.Curr.Microbiol.App.Sci. 10(01): 3445-3454. doi: https://doi.org/10.20546/ijcmas.2021.1001.406 